Original Research Paper

\title{
From Hyperthermia to Immunomodulating Polysaccharides
}

\author{
${ }^{1}$ Novak Miroslav and ${ }^{2}$ Vetvicka Vaclav \\ ${ }^{1}$ University of Chemistry and Technology in Prague, Prague, Czech Republic \\ ${ }^{2}$ Department of Pathology, University of Louisville, Louisville, KY, USA
}

Article history

Received: 15-12-2016

Revised: $16-12-2016$

Accepted: 29-03-2017

Corresponding Author:

Vetvicka Vaclav

Department of Pathology,

University of Louisville,

Louisville, KY, USA

Tell: 502-852-1612

Email: Vaclav.vetvicka@louisville.edu

\begin{abstract}
Natural polysaccharides remain overlooked as part of naturally occurring bioactive molecules. The current knowledge results in numerous clinical trials, from first observations of their effects on various diseases to precise chemical characterization and decades of biological evaluation. The aim of this report is to summarize historical perspective of the route from the first anecdotical observation to the current position, with emphasis on some crucial turning points.
\end{abstract}

Keywords: Glucan, History, Thermotherapy, Zymosan, Cancer

\section{Introduction}

The title is not as straightforward as indicated, however, certain relations existed and exist so far and this review strives to mention them. Hyperthermia can be induced by externally brought heat (it is sometimes called thermotherapy) or for curative purposes, artificially provoked "true" fever caused by infection; the second case is denoted pyrotherapy. While the classical pyrotherapy, whose application culminated in the first half of the last century, is used only rarely for it can bring many negative consequences, certain kinds of thermotherapy, such as contact heating, shortwave diathermy, infrared heating, ultraviolet therapy, microwave thermotherapy, paraffin baths, etc., are in indicated cases used routinely.

The curative effects of elevated body temperature have been known since long ago. In ancient times there was a saying, "Give me the power to produce fever and I'll cure all diseases," attributed alternately to Hippocrates of Kos, Parmenides of Elea or Galen of Pergamum. Hippocrates wrote about the beneficial effects of fever to epilepsy and Galen described curing a melancholic patient after the attack of quartan malaria (Coxe, 1846). Even in the modern age using therapy with increased temperature experienced considerable curative achievements.

A historic example of thermotherapy was the treatment of syphilis, which epidemically spread in Europe in the $15^{\text {th }}$ century and with the high virulence and very pernicious symptoms afflicted populations of all social classes; the epidemic spreading of syphilis was supported by mass movement of army troops as well as civilians. It is very probable that the infection was brought to Europe by Columbian sailors from the Caribbean, where treponematoses are endemic (Rothschild, 2005). Besides mercury preparations, obligatory used for the treatment any skin conditions, or a guaiac wood extract, during those times sudatory baths were used for syphilis treatment (Paracelsus, 1530). These procedures represented a really torturing method, a more modest way consisted of closing a patient in an overheated room for several hours or days, in the rougher manner, dropping him into steaming horse manure. Results of these methods, taking advantage of thermosensitivity of spirochaetes, were uncertain since for the total eradication of the infection rather high temperature is necessary and on top of that, not everyone survives such a procedure.

\section{Pyrotherapy in Modern Medicine}

Application of pyrotherapy in modern medicine is dated to the end of 19th century. In this time, many cases were described about amelioration of paralytics after infection of feverish illnesses, e.g., pneumonia, erysipelas, typhus, etc. This information inspired an Austrian psychiatrist Julius Wagner-Jauregg to experiment with different pyrogens to treat general paresis, non-curable and perniciuos during these times. From a series of tested pyrogens, among others tuberculin, infection of Spirillum minus or erysipelas streptococci, etc., the best results were obtained by the infection of malarial plasmodia (Wagner-Jauregg, 1922). Using combination with other customary used treponemocidal drugs (Salvarsan, compounds of iodine 
or bismuth), remissions even total recovery were achieved; as matter of course, after the therapy it was necessary to cure the malaria. Wagner-Jauregg was awarded by Nobel Prize for medicine in 1927 for these methods. In the 40's of the last century this somewhat dangerous thermotherapy was substituted by penicillin and later by other antibiotics, but was probably still used in 70's (Heimlich, 1993).

In the 19th century it was also known that certain infectious diseases have beneficial therapeutic effects on malignant proliferation. This effect was also ascribed to accompanying temperature elevation; today, of course, it is known that it is predominantly the consequence of immunopotentiating effects of the infection resulting in changes of homeostasis mediators. The first purposed utilization of this effect is dated to the 50's of the $19^{\text {th }}$ century, when Busch (1968) tried to utilize fever, caused by the infection of erysipelas, so by $\beta$-hemolytic streptococci of group A, as treatment for the sarcoma localized in the soft tissue of a patient. Really, time-limited remission occurred, but the total course of the ailment was not managed. Three decades later the use of erysipelas for curing of pernicious tumors was studied more steadily by William B. Coley, probably having not known the pioneer work of Busch (Coley, 1891). First, Coley used injections of live cultures of Streptococcus pyogenes (Bickels et al., 2002; Coley, 1893), but in this insecure method he later replaced live cultures with heat inactivated ones. As it was known that virulence of the streptococci increased at the presence of Serratia marcescens (in those times this red-pigmented microbe was called Bacillus prodigiosus) he combined streptococci with this microbes; the combination of cultures of these two microbes, inactivated by heating to $75^{\circ} \mathrm{C}$, is known as the Coley's toxin or the Coley's vaccine (Coley, 1894). Application of the Coley's toxin leads to violent increasing of the body temperature to $40-40.5^{\circ} \mathrm{C}$. Coley applied his toxin-more or less successfully to inoperable sarcomas of the soft tissues (Coley, 1910; 1928), but also to metastases to the long bones (Coley, 1913). It is interesting that at present there are attempts made to revive the application of Coley's toxin to tumor treatment (Maletzki et al., 2012), despite too risky combination of dangerous pathogensstreptococcal infections are well known and also Serratia is not an innocent microbe, but an opportunistic pathogen, the agent of torpid nosocomial infections.

\section{Lipopolysaccharide}

The presence of Gram-negative Serratia led to supposition that the active pyrogenic agent in the Coley's should be lipopolysaccharides (LPS, endotoxins, toxic polysaccharides), which are the typical component of all Gram-negative microorganisms. As was found later, this supposition was not correct, for the pyrogenicity was not the main curative effect and beneficial outcomes of Coley's toxin relate to function manifestation of interleukin IL-12 (Tsung and Norton, 2006) or tumoricidal activities of pigments prodigiosins (Chang et al., 2011; Stankovic et al., 2014; Darshan and Manonmani, 2015). However, during past times the mentioned supposition led to an attempt to replace the arguable intact microbes, though inactivated, by isolated and purified lipopolysaccharides.

Lipopolysaccharides are contained in outer membranes of all Enterobacteriaceae and most of the other Gram-negative microbes; LPS represents here up to $75 \%$ of the cell surface (Molinaro et al., 2002). General scheme of the LPS structure is preserved at all Gram-negative microorganisms, but in details it can dramatically differ. At different microorganisms and even at serotypes of the same microbe substantial differences can be found first of all in the polysaccharide moiety. At the external end of a lipopolysaccharide complex polysaccharide with antigen properties $(O-$ antigen, OPS) is bound, having up to 40 monosaccharide units. This long polysaccharide is linked to several molecules of fatty acids (antigen $A$ ) through the central oligosaccharide core, 3-deoxy-D-mano-oct-2-ulosonic acid (Kdo) (Molinaro et al., 2002; 2015) and glucosaminyl$\beta(1-6)$-D-glucosamine, usually fosforylated in positions 1 and 4 . The fatty acids are anchored in the outer cell membrane and form its constituent part. In the $O$ antigens of different microbial origin more than 60 monosaccharidic and about 30 non-saccharidic moieties were detected (Raetz and Whitfield, 2002). The fatty acids usually contain 12-16 carbon atoms and tend to be hydroxylated on the third carbon atom (Raetz, 1990).

One of the first research studies of the medicinal application of isolated lipopolysaccharides was Shear, who worked with purified LPSs from Serratia marcescens and Escherichia coli. Shear published several papers (see for example citations (Shear and Turner, 1943; Shear, 1944); from these times there were published hundreds of papers dealing with physiological effects of LPSs from different sources.

In mammals, lipopolysaccharides act as a considerable stimulator of the innate immune system through the mediation of TLR4 (Poltorak et al., 1998; Kalis et al., 2003) or, as was recently found, even of intracellular receptors (Kayagaki et al., 2013) activating caspase-11 (Hagar et al., 2013). When LPSs are applied parenterally, considerable hyperthermia occurs, accompanied by a strong inflammatory response leading to increasing resistance against infection, as well as to regression of tumors via activation of TNF; the hyperthermia itself is only a concomitant reaction and does not represent the essence of the LPSs impact. 
Massive immune response, however, induces very unfavorable side effects, such as diarrhea, leucopenia, hypotensive shock, intravascular coagulation and in the worst cases septic shock and Multiple Organ Dysfunction Syndrome (MODS). The curative effect of LPSs is then considerably doubtful. Even if we could to eliminate these side effects by careful dosage, during protracted treatment LPSs lose efficacy due to quickly developing tolerance (Zeissberger and Roth, 1998; Cavaillon et al., 2003).

Many authors studied composition as well as toxicity of lipopolysaccharides (see reviews (Nowotny, 1963; Lüderitz et al., 1966; Raetz, 1990); probably the most complete is the review of Nowotny (1969). For the subsequent development it is important that as the toxic principle of LPS was identified lipid A, the true endotoxin (e.g., Gardner et al., 1939; Westphal and Luderitz, 1954) whilst the polysaccharide subunit $(O-$ antigen) acted as an antigen determinant; when $O$ antigen is missing, antigen properties are determined by the oligosaccharide core. The primary role of the polysaccharide subunit is protective and the unit is practically non-toxic (Raetz and Whitfield, 2002).

These findings logically started the investigation of different bacterial polysaccharides, not only those contained in LPS. So for example, in the 40's of the last century, Shear and coworkers isolated from the culture of Serratia marcescens a substance, which caused necrosis of tumors, as mentioned above (Shear and Turner, 1943). Lately, Srivastava and Adams (1962) found that it was a mix of three different polysaccharides with similar chemical structure. Their main chain contains D-glucose and D-mannose units linked by (1-3)-glycosidic bonds. Some glucose units are branched on C-2 and C-4 and polysaccharides differ in the degree of that branching and also in the ratio of both sugar components.

\section{Zymosan}

In regard to justified distrust of bacterial sources of polysaccharides, attention gradually shifts to much less dangerous microorganisms, first of all to yeasts. Their intact cells could be, of course, also pyrogenic (Kobayashi and Friedman, 1964) and pyrogenic was also the first isolate from them-zymosan (Hinz et al., 1961), which will be mentioned below. Of course, this pyrogenicity, given mostly by contaminating proteins, is negligible compared to the other effects. Pure isolated polysaccharides are apyrogenic and their biological effects have nothing to do with it.

In the 40's of the last century, Pillemer and Ecker isolated by the alkaline extraction of intact cells of Saccharomyces cerevisiae an insoluble fraction (Pillemer and Ecker, 1941), which inhibited the third component of complement (C3). This preparation was named zymin or Ecker fraction and lately zymosan; a mention of inactivation of complement by yeast cells is substantially older (von Dungern, 1900), though. Coincidentally, at the same time Pillemer and coworkers isolated protein from the human serum as well as sera of different mammals, which destructed bacteria and neutralized viruses by activation of complement without participation of antibodies. They named the protein properdin (from Latin perdere, to destroy, kill) and described its role in the immune system in a series of papers (the first was published in 1954 (Pillemer et al., 1954), the last one in 1957 (Pillemer et al., 1957). In these papers they mentioned the effect of zymosan on the level of properdin in the serum. In the course of time, the "properdine system" was refused and at last rehabilitated (Kemper and Hourcade, 2008; Harboe et al., 2012), but did not influence the fate of zymosan, which began to be applied in many other cases; today zymosan is even commercially available. Zymosan is primarily a potent stimulator of alveolar macrophages and among others induces the release of a series of cytokines, first of all IL-8, from human neutrophils.

\section{$\beta$-Glucan}

Even though zymosan was able to stimulate nonspecific immune response, it was not clear which of its components was responsible for that activity. Actually, zymosan is not a pure polysaccharide but rather a crude insoluble product which contains about $50 \%$ of $\beta$-glucan and also around $17 \%$ of mannan, $14 \%$ of a protein and some ballast substances (DiCarlo and Fiore, 1958). Detailed investigation led to the conclusion that the active component, responsible for the primary effect of zymosan, is branched polysaccharide $\beta(1-3), \beta(1-6)-\mathrm{D}-$ glucan (Riggi and DiLuzio, 1961; Pontieri et al., 1963; Czop and Austen, 1985; Williams et al., 1986) (hence shortly: $\beta$-glucan). Probably the first attempt to compare physiological effects of pure $\beta$-glucan and zymosan was done by a team from Tulane University in New Orleans, headed by Nicholas DiLuzio et al. (1970). This polysaccharide forms a substantial part of the cell walls of yeast and also many micro- or macromycetes (Table 1). From the point of view of immunological functions it is important that $\beta$-glucan, except for some harmless yeasts, is also an obligate component of the cell wall of human pathogenic fungi, such as Candida albicans, Aspergillus fumigatus, Cryptococcus neoformans, Histoplasma capsulatum, Coccidioides immitis and others. This is the main reason immune reactions trigger after contact of $\beta$-glucan with the proper receptor on certain immune cells (macrophages, monocytes, dendritic cells, neutrophils). 
Table 1. Composition of cell wall polysaccharides of some "fungi"

\begin{tabular}{|c|c|c|c|c|c|}
\hline Kingdom & Division & Class & Order & Genus and Species & $\begin{array}{l}\text { Prevailing wall polysaccharides } \\
\text { at vegetative cells } \mathrm{s}^{\mathrm{a}}\end{array}$ \\
\hline Protista & Myxomycota & Acrasiomycetes & Dictyosteliales & Dictyostelium discoideum & Cellulose, glycogen \\
\hline Chromista & Ooomycota & Oomycetes & Peronosporales & $\begin{array}{l}\text { Plasmopara viticola } \\
\text { Phytophora infestans }\end{array}$ & Cellulose, $\beta$-glucan \\
\hline \multirow{9}{*}{ Fungi } & & Hyphochytridiomycetes & Hypochytriales & Rhizidiomyces parasiticus & Cellulose, chitin \\
\hline & Chytridiomycota & Chytridiomycetes & Blastocladiales & Blastocladiella emersonii & chitin, $\beta$-glucan \\
\hline & \multirow[t]{3}{*}{ Eumycota } & Zygomycetes & Mucorales & Muсог тисеdo & chitin, chitosan \\
\hline & & Ascomycetes & Eurotiales & Aspergillus fumigatus & chitin, $\beta$-glucan \\
\hline & & Hemiascomycetes & Saccharomycetales & $\begin{array}{l}\text { Saccharomyces cerevisiae } \\
\text { Candida albicans }\end{array}$ & $\begin{array}{l}\beta \text {-glucan, mannan } \\
\text { mannan }\end{array}$ \\
\hline & Ascomycota & Eurotiomycetes & Onygenales & Coccidioides immitis & $\beta$-glucan, chitin, mannans \\
\hline & & & & Histoplasma capsulatum & $\beta$-glucan, $\alpha$-glucan, chitin \\
\hline & & & & Blastomyces dermatitidis & \\
\hline & & & & Paracoccidioides brasiliensis & \\
\hline
\end{tabular}

There are various natural sources of $\beta$-glucans it can be isolated from yeast, mushrooms, seaweed, bacteria, various grains and even protozoa. However, there are three main sources: Mushrooms, yeast and grain. The reasons are mainly historical the Western civilization has consumed both bread and beer for centuries, therefore there is a significant surplus of yeast. Similarly, the Far East is known for adding mushrooms to the regular diet and various mushrooms are part of the old folk remedies. Grain glucans are the result of a surplus of various grains in Canada and Australia.

It is necessary to mention another way leading to information about specific physiological properties of isolated $\beta$-glucan. Studies of remedial character of medicinal Asian fungi (shitake-Lentinula (Lentinus) edodes, maitake-Grifola frondosa, hiratake-Pleurotus ostreatus and some others) showed that these fungi, besides other physiologically active compounds, contain mainly $\beta$-glucan. Pioneering work done by Goro Chihara from the National Cancer Center in Tokyo, who isolated it from Lentinula edodes, named such isolate lentinan (Chihara et al., 1969). In the course of time, both of the ways mentioned gradually converted. First reports, however, can be traced to the study of Ringler and Lukas et al. (1957). Decades of research revealed several types of action. The first level of action is active in the early stages of carcinogenesis and involves enhancement of several facets of immune response, including IL-1, IFN- $\gamma$, TNF- $\alpha$ and IL-12 production, NK cell activity and macrophage activation (Vetvicka and Vetvickova, 2015). The role in NK cell reconstruction during cancer treatment seems to be particularly important (Pohorska et al., 2016). Another level of protection involves an increase of antioxidant capacity and detoxification of mutagenic compounds (Fujimiya et al., 1988).

The third, clinically possibly the most relevant, effects involved cooperation with anti-tumor antibodies. In vitro and in vivo data indicated that a combination of antibodies and glucan offers superior effects (Liu et al., 2009a), making it an extremely important finding.
Normally, the majority of malignant cells in solid tumors are naturally targeted with $\mathrm{C} 3$ fragment. Freshly excised tumors and established cancer cell lines were examined for tumor opsonization and natural antibodies and the opsonization with circulating anti-tumor antibodies and C3 was confirmed (Niculescu et al., 1992).

Humanized anti-cancer monoclonal antibodies (such as Herception Avastin, Rituximab or Erbitux) are currently widely used to treat tumors (Adams and Wiener, 2005), despite often questionable results. One possible solution is to use these antibodies in combination with common chemotherapy, often increasing adverse side effects. Studies showing that yeast-derived glucans can augment anti-tumor antibody efficacy to treat cancer (Hong et al., 2003; 2004; Yan et al., 1999) were confirmed using barley-derived glucan leading to clinical investigation in Phase II trials (for review see Liu et al. (2009b). As these effects cannot be reproduced in C3or CR3-deficient mice, the importance of CR3 and C3 is clear (Yan et al., 1999). As phagocytosis of glucan does not require CR3, this uptake suggested that in addition to CR3, other glucan receptors, including Dectin-1, have to participate.

Despite decades of research and numerous clinical trials, anti-tumor effects of glucans and the underlying mechanisms are still not fully understood. Some studies showed that besides direct stimulation of immune reactions, up-regulated expression of the tumor suppressor gene p53, cell cycle arrestin p21 and proapoptotic proteins Bax and caspase 3/9 are involved (Xu et al., 2016). Similarly, suppression of VEGF expression leading to slower tumor progression was documented (Xu et al., 2016). Readers keen to see a recent summary of our knowledge of glucan's role in cancer inhibition should read some recent excellent reviews (Vannucci et al., 2013; Sima et al., 2015).

Decades of intensive research revealed significant biological effects of $\beta$-glucans. First, the attention was focused on immunostimulation, from stimulation of hematopoiesis (Patchen et al., 1988) to potentiation of anti-infectious immunity (Hadden, 1987; Spruijt et al., 
2010) and finally suppression of cancer development (Nakao et al., 1983; Hong et al., 2003). Besides these well-established effects, $\beta$-glucan was also found to improve HDLC and diminish LDLC and non-HDL cholesterol levels in overweight individuals with mild hypercholesterolemia (Reyna-Villasmil et al., 2007) to potentiate the methotrexate treatment of adjuvant arthritis (Rovensky et al., 2011) and to improve wound healing. These claims have already resulted in a commercially available $\beta$-glucan-collagen matrix that combines $\beta$-glucan with collagen and has proven to have excellent results in the successful treatment of burns in children (Delatte et al., 2001).

More and more attention has been focused on the role of $\beta$-glucan in inflammation. Some additional and lesser known effects of $\beta$-glucan include the attenuation and even the prevention of experimental colitis. Several experimental studies showed that orally-administered $\beta$-glucan caused significant inhibition of inflammation, production of proinflammatory cytokine interleukin 1 beta and colon shortening. Some studies have shown that $\beta$-glucan plays an important role as an immunomodulator in the treatment of ulcerative colitis (Nosalova et al., 2001). We cannot overlook the effects of glucan on stressbesides direct effects on stress reduction (Vetvicka and Vetvickova, 2014), clinical trials also found improvements of physical conditions in children under stress (Richter et al., 2015).

Lately, $\beta$-glucans are finding their role not "only" in immunostimulation and overall health improvement, but also in nutrition. A study on fish showed that using $\beta$ glucan as a probiotic supporting the activity of Lactobacillus significantly lowered mortality from Aeromonas challenges (Ngamkala et al., 2010). However, more has been done on the prebiotic front. An interesting study showed that the addition of $\beta$-glucan and starch during cold storage strongly increased survival of bifidobacteria strains in yogurt, most probably due to the protective effects on bifidobacteria stress by low temperature (Rosburg et al., 2010). Another $\beta$-glucan with high prebiotic properties was isolated from Lactobacillus plantarum (Das et al., 2014). Similar effects were obtained when shrimp was used as an experimental model.

The situation in calves is similar: Feeding with tylosin and $\beta$-glucan as prebiotics has positive effects on selected humoral immunological parameters, including the total protein and gammaglobulin concentration (Szymanska-Czerwinska and Bednarek, 2011). Prebiotic potential of $\beta$-glucan was also tested on humans. A randomized, double-blind, placebo-controlled clinical study was aimed to evaluate the in vivo prebiotic potential of $\beta$-glucan. Fifty-two healthy volunteers were assigned to consume a $\beta$-glucan or placebo daily for 30 days. In volunteers over 50 years of age, $\beta$-glucan induced a strong bifidogenic affect and increase of bifidobacteria. The authors of this study concluded that the daily intake of a $\beta$-glucan was not only welltolerated, but demonstrated strong bifidogenic properties in older, healthy volunteers consuming their usual food (Mitsou et al., 2010).

\section{Conclusion}

It is clear that it took polysaccharides a long time to reach their true potential. Even if it is true that after centuries of sometimes intensive research, our knowledge of their biological effects is far from optimal, there are no doubts about their importance. However, the process of accepting natural molecules is a long process, it took over 70 years to accept that vitamin $\mathrm{C}$ cures scurvy. It may take repetitious studies and years or even decades before individual polysaccharides will be credited for their role in health improvements.

\section{Funding Information}

This study was funded by Department of Pathology.

\section{Author's Contributions}

All authors equally contributed to this study.

\section{Conflict of Interest}

Authors declare no conflict of interest.

\section{References}

Adams, G.P. and L.M. Weiner, 2005. Monoclonal antibody therapy of cancer. Nat. Biotechnol., 23: 1147-1157. DOI: $10.1038 /$ nbt1 137

Bickels, J., Y. Kollender, O. Merinsky and I. Meller, 2002. Coley's toxin: Historical perspective. Israel Med. Assoc. J., 4: 471-472. PMID: 12073431

Busch, W., 1968. Verhandlungen artzlicher Gesellschaften. Sitzung der mediciniscben Section vom 18. Berl. Klin. Wochenschr., 5: 137-138.

Cavaillon, J.M., C. Adrie, C. Fitting and M. AdibConquy, 2003. Endotoxin tolerance: Is there a clinical relevance? J. Endotox. Res., 9: 101-107. DOI: 10.1179/096805103125001487

Chang, C.C., W.C. Chen, T.F. Ho, H.S. Wu and Y.H. Wei, 2011. Development of natural anti-tumor drugs by microorganisms. A review. J. Biosci. Bioeng., 111: 501-511. DOI: 10.1016/j.jbiosc.2010.12.026

Chihara, G., Y.Y. Maeda, J. Hamuro, T. Sasaki and F. Fukuoka, 1969. Inhibition of Mouse Sarcoma 180 by polysaccharides from Lentinus edodes (Berk.) Sing. Nature, 222: 687-688.

DOI: $10.1038 / 222687 \mathrm{a} 0$ 
Coley, W.B., 1891. Contribution to the knowledge of sarcoma. Ann. Surgery, 14: 199-220. DOI: $10.1097 / 00000658-189112000-00015$

Coley, W.B., 1893. The treatment of malignant tumors by repeated inoculations of erysipelas: With a report of ten original cases. Am. J. Med. Sci., 105: 487-511. DOI: $10.1097 / 00000441-189305000-00001$

Coley, W.B., 1894. Treatment of inoperable malignant tumors with the toxines of erysipelas and the bacillus prodigiosus. Am. J. Med. Sci., 108: 50-66. DOI: $10.1097 / 00000441-189407000-00006$

Coley, W.B., 1910. The treatment of inoperable sarcoma by bacterial toxins (the mixed toxins of the Streptococcus erysipelas and the Bacillus prodigiosus). Proc. R. Soc. Med., 3: 1-48. PMID: 19974799

Coley, W.B., 1913. Contribution to the study of sarcoma of the femur. Ann. Surgery, 58: 97-108. DOI: $10.1097 / 00000658-191307000-00010$

Coley, W.B., 1928. End results in Hodgkin's disease and lymphosarcoma treated by the mixed toxins of erysipelas and Bacillus prodigiosus, alonis or combined with radiation. Ann. Surgery, 58: 641-667. DOI: $10.1097 / 00000658-192810000-00002$

Coxe, J.R., 1846. The Writings of Hippocrates and Gallen: Epitomised from the Original Latin Translations. 1st Edn., Lindsay and Blakiston, Philadelphia.

Czop, J.K. and K.F. Austen, 1985. Properties of glycans that activate the human alternative complement pathway and interact with the human monocyte $\beta$ glucan receptor. J. Immunol., 134: 2588-2593. PMID: 4045195

Darshan, N. and K. Manonmani, 2015. Prodigiosin and its potential applications. J. Food Sci. Technol., 52: 5393-5407. DOI: 10.1007/s13197-015-1740-4

Das, D., R. Baruah, R., A. Goyal, 2014. A food additive with prebiotic properties of an $\alpha$-D-glucan from Lactobacillus plantarum DM5. Int. J. Biol. Macromol., 69: 20-26.

DOI: 10.1016/j.ijbiomac.2014.05.029

Delatte, S.J., J. Evans, A. Hebra, W. Adamson and H.B. Othersen et al., 2001. Effectiveness of beta-glucan collagen for treatment of partial-thickness burns in children. J. Pediat. Surgery, 36: 112-118.

DOI: $10.1053 /$ jpsu.2001.20024

DiCarlo, F.J. and J.V. Fiore, 1958. On the composition of zymosan. Science, 127: 756-757. DOI: 10.1126/science.127.3301.756-a

DiLuzio, N.R., J.C. Pisano and T.M. Saba, 1970. Evaluation of the mechanism of glucan-induced stimulation of the reticuloendothelial system. J. Reticulo-Endothel. Soc., 7: 731-742.

PMID: 5432023
Fujimiya, Y., Y. Suzuki, K. Oshiman, H. Kobori and K. Moriguchi et al., 1998. Selective tumoricidal effect of soluble proteoglucan extracted from the basidiomycete, Agaricus blazei Murill, mediated via natural killer cell activation and apoptosis. Cancer Immunol. Immunotherap., 46: 147-159.

DOI: $10.1007 / \mathrm{s} 002620050473$

Gardner, R.E., G.H. Bailey and R.R. Hyde, 1939. Hemorrhagic activity of toxic carbohydrate complexes from bacteria on transplantable rat tumor. Am. J. Hyg., 29B: 1-14.

Hadden, J.W., 1987. Immunopharmacology of the immunotherapy of cancer, infection and autoimmunity. Fundam. Clin. Pathol., 1: 283-296. DOI: $10.1111 /$ j.1472-8206.1987.tb00566.x

Hagar, J.A., D.A. Powell, Y. Aachoui, R.K. Ernst and E.A. Miao, 2013. Cytoplasmic LPS activates caspase-11: Implications in TLR4-independent endotoxic shock. Science, 341: 1250-1253. DOI: $10.1126 /$ science. 1240988

Harboe, M., P. Garred, J.K. Lindstad, M. Pharo and F. Müller et al., 2012. The role of properdin in zymosan- and Escherichia coli-induced complement activation. J. Immunol., 189: 2606-2613.

DOI: $10.4049 /$ jimmunol.1200269

Heimlich, H.J., 1993. Malaria therapy: The value of the randomized controlled trial. J. Am. Med. Assoc., 269: 211-212. DOI: 10.1001/jama.1993.03500020045014

Hinz, C.F., R.J. Wedgwood, L. Pillemer, 1961. The properdin system and immunity. XV. Some biologic effects of the administration of zvmosan and other polvsaccharides to rabbits and the presence of antibodies to zymosan in human and rabbit serum. J. Lab. Clin. Med., 57: 185-198. PMID: 13714488

Hong, F., R.D. Hansen, J. Yan, D.J. Allendorf and J.T. Baran et al., 2003. $\beta$-Glucan functions as an adjuvant for monoclonal antibody immunotherapy by recruiting tumoricidal granulocytes as killer cells. Cancer Res., 63: 9023-9031. PMID: 14695221

Hong, F., J. Yan, J.T. Baran, D.J. Allendorf and R.D. Hansen et al., 2004. Mechanism by which orally administered $\beta-\beta-1,3$-glucans enhance the tumoricidal activity of antitumor monoclonal antibodies in Murine tumor models. J. Immunol., 173: 797-806. DOI: 10.4049/jimmunol.173.2.797

Kalis, C., B. Kanzler, A. Lembo, A. Poltorak and C. Galanos et al., 2003. Toll-like receptor 4 expression levels determine the degree of LPS-susceptibility in mice. Eur. J. Immunol., 33: 798-805.

DOI: $10.1002 /$ eji.200323431

Kayagaki, N., M.T. Wong, I.B. Stowe, S.R. Ramani and L.C. Gonzalez et al., 2013. Noncanonical inflammasome activation by intracellular LPS independent of TLR4. Science, 341: 1246-1249. DOI: $10.1126 /$ science. 1240248 
Kemper, C. and D.E. Hourcade, 2008. Properdin: New roles in pattern recognition and target clearance. Mol. Immunol., 45: 4048-4056.

DOI: 10.1016/j.molimm.2008.06.034

Kobayashi, G.S. and L. Friedman, 1964. Characterization of the pyrogenicity of Candida albicans, Saccharomyces cerevisiae and Cryptococcus neoformans. J. Bact., 88: 660-666. http://jb.asm.org/content/88/3/660.abstract

Liu, J., L. Gunn, R. Hansen and J. Yan, 2009a. Combined yeast-derived $\beta$-glucan with anti-tumor monoclonal antibody for cancer immunotherapy. Exp. Mol. Pathol., 86: 208-214. DOI: 10.1016/j.yexmp.2009.01.006

Liu, J., L. Gunn, R. Hansen and J. Yan, 2009b. Yeastderived $\beta$-glucan in combination with anti-tumor monoclonal antibody therapy in cancer. Recent Pat. Anticancer Drug Discov., 4: 101-109. DOI: $10.2174 / 157489209788452858$

Lüderitz, O., A.M. Staub, O. Westphal, 1966. Immunochemistry of $O$ and $R$ antigens of Salmonella and related Enterobacteriaceae. Bact. Rev., 30: 192-232. PMID: 5324647

Lukas, E.H., R.L. Ringler, R.U. Byerrum, J.A. Stevens and D.A. Clarke et al., 1957. Tumor inhibitors in Boletus edulis and other holobasidiomycetes. Antibiot. Chemother., 7: 1-14. PMID: 24544235

Maletzki, C., U. Klier, W. Obst, B. Kreikemeyer and M. Linnebacher, 2012. Reevaluating the concept of treating experimental tumors with a mixed bacterial vaccine: Coley's toxin. Clin. Dev. Immunol., 2012: 230625-230640. DOI: $10.1155 / 2012 / 230625$

Mitsou, E.K., N. Panopoulos, K. Turunen, V. Spiliotis and A. Kyriacou, 2010. Prebiotic potential of barley derived $\beta$-glucan at low intake levels: A randomised, double-blinded, placebo-controlled clinical study. Food Res. Int., 43: 1086-1092. DOI: 10.1016/j.foodres.2010.01.020

Molinaro, A., C. De Castro, R. Lanzetta, A. Evidente and M. Parrilli et al., 2002. Lipopolysaccharides possessing twol-glycero-d-manno-heptopyranosyl$\alpha$ - $(1 \rightarrow 5)-3$-deoxy-d-manno-oct-2-ulopyranosonic acid moieties in the core region. J. Biol. Chem., 277: 10058-10063. DOI: 10.1074/jbc.M1 10283200

Molinaro, A., O. Holst, F. Di Lorenzo, M. Callaghan and A. Nurisso et al., 2015. Chemistry of lipid A: At the heart of innate immunity. Chem. Eur. J., 21: 500-519. DOI: $10.1002 /$ chem. 201403923

Nakao, I., H. Uchino, I. Kaido, T. Kimuira and T. Goto et al., 1983. Clinical evaluation of schizophyllan (SGP) in advanced gastric cancer-a randomized comparative study by an envelope method. Jpn. J. Cancer Chemotherap., 10: 1146-1159.
Ngamkala, S., K. Futami, M. Endo, M. Maita and T. Katagiri, 2010. Immunological effects of glucan and Lactobacillus rhamnosus GG, a probiotic bacterium, on Nile tilapia Oreochromis niloticus intestine with oral Aeromonas challenges. Fisheries Sci., 76: 833-840. DOI: 10.1007/s12562-010-0280-0

Niculescu, F.H., G. Rus, M. Retegan and R. Vlaicu, 1992. Persistent complement activation on tumor cells in breast cancer. Am. J. Pathol., 140: 1039-1043. PMID: 1374587

Nosalova, V., P. Bobek, S. Cerna, S. Galbavy and S. Stvrtina, 2001. Effects of Pleuran ( $\beta$-glucan isolated from Pleurotus ostreatus) on experimental colitis in rats. Physiol. Res., 50: 575-581. PMID: 11829318

Nowotny, A., 1963. Relation of structure to function in bacterial $O$ antigens. II. Fractionation of lipids present in bovin-type endotoxin. J. Bacteriol., 85: 427-435.

Nowotny, A., 1969. Molecular aspects of endotoxic reactions. Bact. Rev., 3: 72-98.

Paracelsus, T., 1530. Von der Frantzosischen Kranckheit drey Bucher. 1st Edn., Friederich Peypus, Nurmberg.

Patchen, M.L., T. Vaudrain, H. Correira, T. Martin and D. Reese, 1988. In vitro and in vivo hematopoietic activities of Betafectin PGG-glucan. Exp. Hematol., 13: 1247-1254. PMID: 9845381

Pillemer, L., L. Blum, I.H. Lepow, O.A. Ross and E.W. Todd et al., 1954. The properdin system and immunity. I. Demonstration and isolation of a new serum protein, properdin and its role in immune phenomena. Science, 120: 279-285. PMID: 13186838

Pillemer, L. and E.E. Ecker, 1941. Anticomplementary factor in fresh yeast. J. Biol. Chem., 137: 139-142. http://www.jbc.org/content/137/1/139.citation

Pillemer, L., M. Landy and M.J. Shear, 1957. The properdin system and immunity: VII. Alterations in properdin levels and resistance to infection in mice following the administration of tissue polysaccharides. J. Exp. Med., 106: 99-110.

Pohorska, J., J. Richter, V. Kral, L. Rajnohova Dobiasova and I. Stiborova et al., 2016. Reconstruction of NK cells during complex cancer treatment. J. Tumor, 4: 398-402. DOI: $10.17554 /$ j.issn.1819-6187.2016.04.86

Poltorak, A., X. He, I. Smirnova, M.Y. Liu and C.V. Huffel et al., 1998. Defective LPS signaling in $\mathrm{C} 3 \mathrm{H} / \mathrm{HeJ}$ and $\mathrm{C} 57 \mathrm{BL} / 10 \mathrm{ScCr}$ mice: Mutations in Tlr4 gene. Science, 282: 2085-2088. DOI: $10.1126 /$ science.282.5396.2085

Pontieri, G.M., O.J. Plescia and W.J. Nickerson, 1963. Inactivation of complement by polysaccharides. J. Bacteriol., 86: 1121-1122. PMID: 14080784

Raetz, C.R.H., 1990. Biochemistry of endotoxins. Annu. Rev. Biochem., 59: 129-170.

DOI: 10.1146/annurev.bi.59.070190.001021 
Raetz, C.R.H. and C. Whitfield, 2002. Lipopolysaccharide endotoxins. Annu. Rev. Biochem., 71: 635-700. DOI: 10.1146/annurev.biochem.71.110601.135414

Reyna-Villasmil, N., V. Bermudez-Pirela, E. MengualMoreno, N. Arias and C. Cano-Ponce et al., 2007. Oat-derived $\beta$-glucan significantly improves HDLC and diminishes LDLC and Non-HDL cholesterol in overweight individuals with mild hypercholesterolemia. Am. J. Therap., 14: 203-212. DOI: 10.1097/01.pap.0000249917.96509.e7

Richter, J., V. Svozil, V. Kral, L. Rajnohova Dobiasova and V. Vetvicka, 2015. $\beta$-Glucan affects mucosal immunity in children with chronic respiratory problems under physical stress: Clinical trials. Ann. Transl. Med., 3: 52-52. DOI: 10.3978/j.issn.23055839.2015.03.20

Riggi, S.J. and N.R. Di Luzio, 1961. Identification of a reticuloendothelial stimulating agent in zymosan. Am. J. Physiol., 200: 297-300. PMID: 13741617

Rosburg, V., T. Boylston and P. White, 2010. Viability of bifidobacteria strains in yogurt with added oat beta-glucan and corn starch during cold storage. J. Food Sci., 75: C439-C444. DOI: 10.1111/j.1750-3841.2010.01620.x

Rovensky, J., M. Stancikova, K. Svik, K. Bauerova and J. Jurcovicova, 2011. The effects of beta- glucan isolated from Pleurotus ostreatus on methotrexate treatment in rats with adjuvant arthritis. Rheumatol. Int., 31: 507-511. DOI: 10.1007/s00296-009-1258-Z

Rothschild, B.M., 2005. History of syphilis. Clin. Infect. Dis., 40: 1454-1463. DOI: 10.1086/429626

Shear, M.J. and F.C. Turner, 1943. Chemical treatment of tumors. V. Isolation of the hemorrhage-producing fraction from Serratia marcescens (Bacillus prodigiosus) culture filtrate. J. Nat. Cancer Inst., 4: 81-97. DOI: $10.1093 /$ jnci/4.1.81

Shear, M.J., 1944. Chemical treatment of tumors. IX. Reactions of mice with primary subcutaneous tumors to injection of a hemorrhage-producing bacterial polysaccharide. J. Nat. Cancer Inst., 4: 461-76. DOI: 10.1093/jnci/4.5.461

Sima, P., L. Vannucci and V. Vetvicka, 2015. Glucans and cancer: Historical perspective. Cancer Translat. Med., 1: 209-214. DOI: 10.4103/2395-3977.172860

Spruijt, N.E., T. Visser and L.P. Leenen, 2010. A systematic review of randomized controlled trials exploring the effect of immunomodulative interventions on infection, organ failure and mortality in trauma patients. Crit. Care, 14: R150R150. DOI: $10.1186 / \mathrm{cc} 9218$

Srivastava, H.C. and G.A. Adams, 1962. Constitutions of polysaccharides from Serratia marcescens. Can. J. Chem., 40: 1415-1424. DOI: 10.1139/v62-217
Stankovic, N., L. Senerovic, T. Ilic-Tomic, B. Vasiljevic and J. Nikodinovic-Runic, 2014. Properties and applications of undecylprodigiosin and other bacterial prodigiosins. Applied Microbiol. Biotechnol., 98: 384385. DOI: $10.1007 / \mathrm{s} 00253-014-5590-1$

Szymanska-Czerwinska, M. and D. Bednarek, 2011. Effect of tylosin and prebiotics on the selected humoral immunological parameters in calves. Med. Wet., 67: 275-278.

Tsung, K. and J.A. Norton, 2006. Lessons from Coley's toxin. Surg. Oncol., 15: 25-28.

DOI: 10.1016/j.suronc.2006.05.002

Vannucci, L., J. Krizan, P. Sima, S. Stakheev and F. Caja et al., 2013. Immunostimulatory properties and antitumor activities of glucans (Review). Int. J. Oncol., 43: 357-364. DOI: 10.3892/ijo.2013.1974

Vetvicka, V. and J. Vetvickova, 2014. Anti-stress action of an orally-given combination of resveratrol, $\beta$ glucan and vitamin C. Molecules, 19: 13724-13734. DOI: $10.3390 /$ molecules190913724

Vetvicka, V. and J. Vetvickova, 2015. Glucan supplementation has strong anti-melanoma effects: Role of NK cells. Anticancer Res., 35: 5287-5292. PMID: 26408688

von Dungern, E., 1900. Beiträge zur Immunitätslehre. Münchener Med. Wochenschr., 47: 677-680.

Wagner-Jauregg, J., 1922. The treatment of general paresis by inoculation of malaria. J. Nerv. Ment. Dis., 55: 369375. DOI: 10.1097/00005053-192205000-00001

Westphal, O. and O. Lüderitz, 1954. Chemische erforschung von lipopolysacchariden gramnegativer bakterien. Angew. Chem., 66: 407-417.

DOI: 10.1002/ange.19540661312

Williams, J.D., N. Topley, H.M. Alobaidi and M.J. Harbek, 1986. Activation of human polymorphonuclear leucocytes by particulate zymosan is related to both its major carbohydrate components: Glucan and mannan. Immunology, 58: 117-124.

Xu, H., S. Zou, X. Xu and L. Zhang, 2016. Anti-tumor effect of $\beta$-glucan from Lentinus edodes and the underlying mechanism. Scientic Rep., 6: $28802-$ 28802. DOI: $10.1038 /$ srep28802

Yan, J., V. Vetvicka, Y. Xia, A. Coxon and M.C. Carroll et al., 1999. $\beta$-glucan, a "specific" biologic response modifier that uses antibodies to target tumors for cytotoxic recognition by leukocyte complement receptor type 3 (CD11b/CD18). J. Immunol., 163: 3045-3052. PMID: 10477568

Zeissberger, E. and J. Roth, 1998. Tolerance to pyrogens. Ann. N.Y. Acad. Sci., 856: 116-131. DOI: $10.1111 /$ j.1749-6632.1998.tb08320.x 